\title{
Benchmarking in Romanian industrial environment
}

\author{
Gina-Maria Moraru ${ }^{1 *}$ \\ 1“"Lucian Blaga” University of Sibiu, gina.moraru@ulbsibiu.ro, Romania
}

\begin{abstract}
Benchmarking is a managerial tool that can assist the organizational change and the innovation. The paper aims to discover the degree in which Romanian managers in various industrial fields use this modern tool in the improvement of business strategy or organizational processes. In this context, we presented some results of a selective research made in Romanian industrial environment. The respondents were experts in creativity management and benchmarking, acting in big, medium or small enterprises. They offered many solutions for increase the rate of use of benchmarking and creativity couple in the management of Romanian organizations.
\end{abstract}

\section{Introduction}

Benchmarking is a process through which participants can identify what they need to improve in organization, learn how to share information with other participants, and discover how to make the best improvements, by APO [1]. Benchmarking can assist the organizational change, by D. Gillen [2], and the innovation, by APO [1]. Experts in various fields can implement creatively in their organizations solutions generated by benchmarking participants, by G.M. Moraru [3] .

In the first stage, a correct benchmarking process will help the management to discover where performance blockages are most serious, APO [1]. Benchmarking can then focus on the areas with problems.

In the elaboration of the business strategy stage, benchmarking can help management to select the optimal improvements by assisting with breakthrough initiatives, proposing new ideas or process innovation, APO [1]. Therefore, managers all around the world use benchmarking as a modern tool to create a complete organizational database for the future innovations. Moreover, it is a management tool for improving the organizational performance, by R. Scott [4].

\section{Selective Research in Romanian Industry}

\subsection{Premises of the Research}

During the last years, we have developed many studies regarding the possibilities of using the benchmarking - creativity couple in organizations, in order to increase their performances, G.M. Moraru [3], and G.M. Moraru [5]. Comparing the Romanian managers' opinions regarding the real use of this couple in organizations, by G.M. Moraru [3], with those of other experts in creativity management and benchmarking, acting in big, medium or small enterprises, by G.M. Moraru [5], we notify that experts are more reserved than managers regarding the use of creativity in Romanian management, but more optimist regarding the use of benchmarking (Fig. 1).

Using a scale from 0 to 5 ( 0 points for "I don't know" and 5 points for the use of the specified element to a very large extent) the averages of experts' responses were 1.917 for creativity and 1.833 for benchmarking. The averages of managers' responses were 2.134 for creativity and 1.354 for benchmarking. These values are under the mean of the scale (2.5) and show a poor use of creativity and benchmarking in Romanian management in the opinions of both categories of respondents.

We have to mention that this paper presents a few results from the phase of a larger research developed with experts in creativity management and benchmarking, acting in big, medium or small enterprises, G.M. Moraru [5].

The first limitation of our study consisted in the difficulty to discover in the Romanian industry these experts. Even academics in Romanian universities and top managers of many firms suggested us a list with the name of experts, based on their professional achievements, many of these people were very modest and did not accept the status of experts. Being in full professional development, they have declared that they do not have enough experience and knowledge to be named "experts".

\footnotetext{
*Corresponding author: gina.moraru@ulbsibiu.ro
} 
The second limitation of this exploratory study partially derived from the first one. If it was difficult for us to convince the experts to participate to the research, it was even more difficult to find experts in creativity management and benchmarking who do not work in research and development but in production, services,

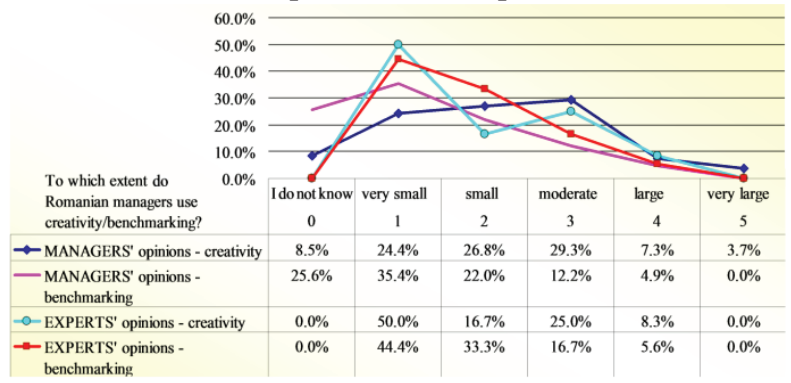

Fig. 1. Comparative opinions of experts and managers regarding the use of benchmarking and creativity in Romanian organizations

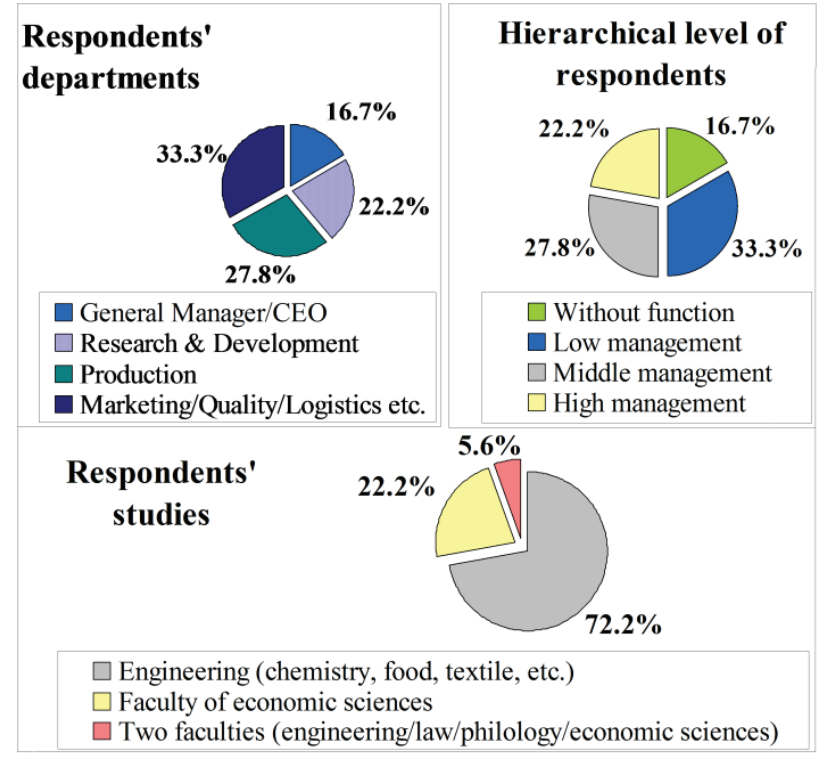

Fig. 2. Respondents' characteristics

So, the sample is not representative for the experts' population. The study is an investigation, not a survey.

\subsection{The main results}

One of the questions asked respondents to formulate solutions for expanding the use of benchmarking and creativity in the management of Romanian organizations. They provided many strategic, tactical and/or operational solutions (Fig. 3). We accorded:

3 points - to the questionnaires with strategic solutions;

2 points - to those with tactical solutions;

1 point - to those with operational solutions;

0 point - to those without solutions.

Using this scale, we obtained an average of 2.056, a standard deviation of 0.893 and a homogeneity coefficient of 0.434 . Even the responses are partial not homogeneous (and the coefficient is between 0.4 and human resources, marketing or finance.

The third limitation of the study is the lack of information regarding the personal characteristics of the whole population of experts in creativity management and benchmarking in Romania. Fig. 2 presents a few of the respondents' characteristics. 0.45), the average obtained show more concerning of the respondents with the strategic measures than with the operational ones. It is a positive aspect that reflects their orientation on long terms.

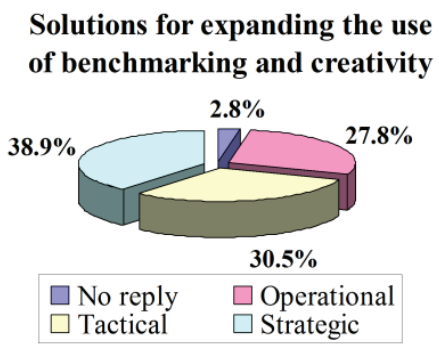

Fig. 3. Experts' suggestions for expanding the use of benchmarking and creativity

We mention the most important strategic solutions provided by respondents:

1) Motivating creativity at all organizational levels;

2) Including creativity in the strategic plans;

3) Making an organizational guide for assessing employees' ideas;

4) Developing the technology transfer chains;

5) Founding scientific concerns in various fields;

6) Assuming the risks of pioneering managerial actions;

7) Ensuring a legislation that stimulates creativity.

From the tactical respondents' suggestions we selected the most relevant ones and we grouped them in several categories:

1) Supporting the research and development of the new products in the organization's own centers;

2) Increasing budgets for research;

3) Developing new projects with universities and research institutes;

4) Lifelong learning, emphasizing the development of human creativity in Romanian organizations;

\section{5) Making national advertising to the firms that used} benchmarking.

Regarding the last proposal, we remember that in the specialty literature there are opinions that support the necessity to establish national specific institutions which are concerned with benchmarking, for the benefit of the national economy, by G.M. Moraru [5].

We enumerate several operational solutions provided by the respondents:

\footnotetext{
*Corresponding author: gina.moraru@ulbsibiu.ro
} 
1) Training all employees for creativity;

2) Combining various managerial methods for

stimulating human resources' creativity;

3) Educating the young managers by the oldest ones in the spirit of customer respect;

4) Creating benchmarking procedures in the company;

5) Rewarding any process, activity or product

improvement made by an employee.

Only $2.8 \%$ of the experts did not answer to this question (Fig. 3).

Another question for the experts in creativity management and/or benchmarking was: "In how many benchmarking trials was your organization involved in the last five years?" We centralized their responses in Fig. 4. We can observe that $66.7 \%$ of respondents declared that their organization was not involved in any benchmarking process in the last five years.

The average of the answers was low, 1.833 on a scale from 1 to 5 . Even if the standard deviation is high 1.404 - and the sample answers are not homogeneous with a homogeneity coefficient of 0.766 , the graphics demonstrates a poor use of benchmarking in Romanian industrial management (Fig. 4).

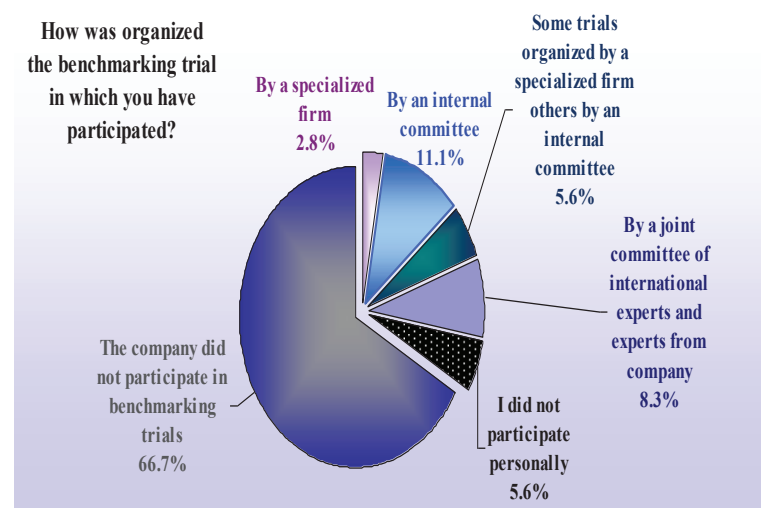

Fig. 4. The organization of benchmarking trials in Romanian industry.

On the second place are the trials organized by a joint committee made from international experts and experts who work in company (8.3\%). So, in Romanian industry, internal benchmarking is preferred to the external one.

Moreover, only $2.8 \%$ of respondents declared that their company was involved in benchmarking trials

\section{In how many benchmarking trials was your organization involved in the last five years?}

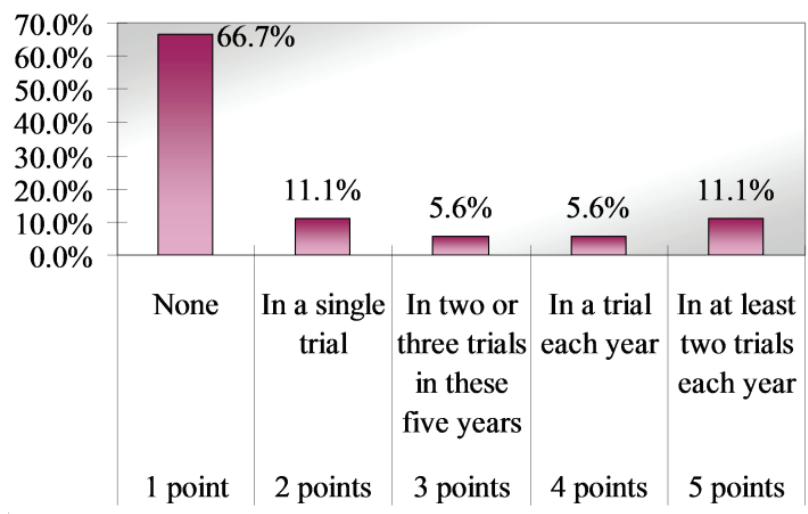

Fig. 5. The number of benchmarking trials in which respondents' organizations were involved.

Then respondents were asked to specify how was organized the benchmarking trial (trials) in which they have participated. Centralizing their answers, we obtain the graphic in Fig. 5. We can see that the most trials were organized by an internal committee (11.1\%). developed by a specialized firm. A possible explanation could be the Romanian managers' reluctance to use benchmarking and share information with other organizations.

We wanted to find out if the specialty literature helps managers and experts to achieve new and important knowledge in the field of creativity management and benchmarking. So, another question was: "Do you think that Romanian literature does provide enough information about:

a) Scientific research in your field?

b) Creativity management?

c) Benchmarking?"

The experts signaled the gap in the Romanian specialty literature with information at all previous points (Fig. 6). For evaluation, we used the scale: 0 points for the answer "no", 1 point for the answer "only on certain aspects" and 2 points for "yes". The averages were very low: 0.361 for information offered in the experts' research fields, 0.278 for those in creativity management, and 0.111 for information about benchmarking. 


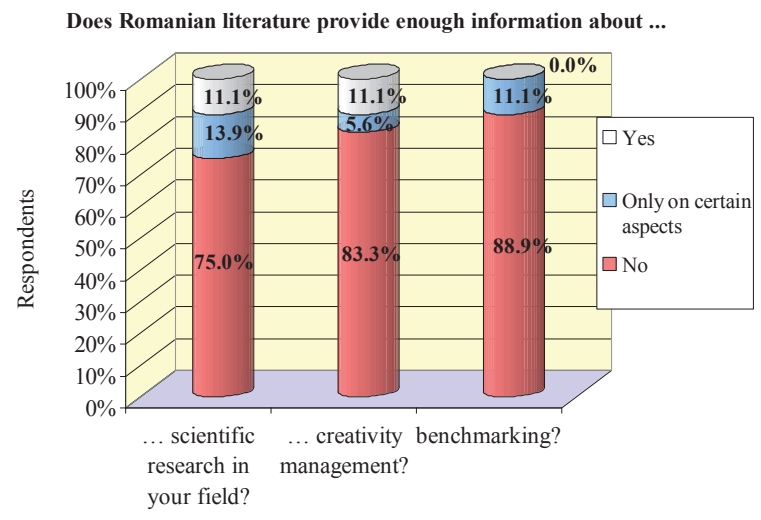

Fig. 6. Experts' opinions regarding the information offered by the Romanian specialty literature.

\section{Conclusions}

Highlighting both organizational problems and their improvement potential, benchmarking is a tool that can support managers in various fields. Modern benchmarking can be developed between partners from various industries (G.M. Moraru [5]), with different functions or locations (S. Rohlfer [6]). Benchmarking can help managers to build learning organizations, by C.J. McNair, K.H.J. Leibfried [7].

We presented some results of a selective research made in Romanian industrial environment, with the aim of discovering the degree in which Romanian managers in various industrial fields use this modern tool in the improvement of business strategy or organizational processes.

Our respondents were experts in creativity management and/or benchmarking, acting in big, medium or small enterprises. They understand one of the most important roles of the modern benchmarking, that of triggering creative ideas through inspiring from similar organizations. They also signaled a gap in the Romanian specialty literature in this field.

The experts in creativity management and/or benchmarking offered many solutions for increase the rate of use of benchmarking - creativity couple in the management of Romanian organizations, in order to improve their performances. We remember only the necessity of developing the technology transfer chains and those of ensuring a legislation framework that stimulates creativity.

\section{Acknowledgment}

This work was supported by the grant LBUS-IRG2016-02, co-financed by the "Lucian Blaga" University of Sibiu (Romania).

\section{References}

[1] Asian Productivity Organization (APO), Benchmarking Training Manual, Tokyo, Japan: APO Best Practice Network, 2005, pp. 115, http://www.apo-tokyo.org/publications/wp-content/uploads/ sites/5/ind-13-bmtm.pdf, accessed on March 2017.

[2] D. Gillen, "Benchmarking and Performance Measurement: The Role in Quality Management", School of Business \& Economics Wilfrid Laurier University Waterloo, Canada, 2000, https:// legacy.wlu.ca/documents/4293/Benchmarking.pdf, accessed on May 2017.

[3] G.M. Moraru, "Creativity and Benchmarking in Romanian Management", EDULEARN15 Poceedings, Barcelona, Spain: IATED Digital Library, 2015, pp. 3996-4002.

[4] R. Scott, "Benchmarking: A Literature Review", Edith Cowan University,

2011 https://intranet.ecu.edu.au/ data/assets/pdf file /0010/357193/Benchmarking-Literature-Review.pdf, accessed on May 2017.

[5] G.M. Moraru, "Creativity Management and Benchmarking Promoting Performance and Competitiveness in Modern Organizations" ("Managementul creativităţii şi benchmarkingul în promovarea performanţei şi competitivităţii în organizaţiile moderne"), PhD Thesis, "Lucian Blaga" University of Sibiu, Romania, sustained April 2011, unpublished to a publishing house

[6] S. Rohlfer, "Benchmarking Concepts in the UK and Germany: Between Standardisation and Local Variation?", Warwick Papers In Industrial Relations, No. 69, University of Warwick, UK: Industrial Relations Research Unit, 2005, pp. 1-36, https://www2.warwick.ac.uk/fac/soc/wbs/research/irru/wpir/wpir sylvia rohlfer.pdf, accessed on May 2017.

[7] C.J. McNair, K.H.J. Leibfried, Benchmarking: A Tool for Continuous Improvement. New York: Wiley, 1993, pp. 320-321.

${ }^{*}$ Corresponding author: gina.moraru@ulbsibiu.ro 